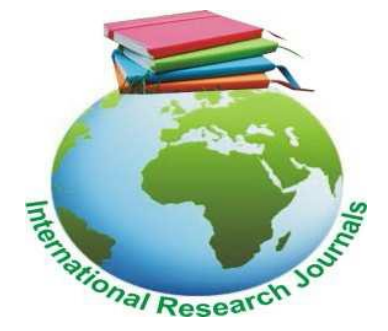

Journal of Research in International Business and Management (ISSN: 2251-0028) Vol. 5(1) pp. 129- 135, February 2019

Available online http://www.interesjournals.org/JRIBM

DOI: http:/dx.doi.org/10.14303/jribm.2018.024

Copyright (c) 2019 International Research Journals

Review article

\title{
Analysis of the impact of logistics technology innovation in supply chain management
}

\section{Sunil Koul}

Enterprise Applications, Restoration Hardware, Corte Madera, California, USA

${ }^{*}$ Corresponding Author's Email: koul sunil@hotmail.com: Tel: (949) 374 - 0552

\section{Abstract}

This article is aimed to critically analyze the responses of the customers relating to their expectations on the logistics technology innovations in the supply chain management. To meet this research aim, theoretical as well as empirical contributions were taken into consideration, wherein two companies were mainly analyzed, i.e., FedEx and DHL. The research method used for meeting the aims as well as objectives were both quantitative and qualitative approaches. In this regard, both secondary, as well as primary sources were used. The primary data was collected from a questionnaire survey and was analyzed by using Pearson's correlation and regression. After the study, it was found that both the companies had a positive impact on the management of customer experiences.

Keywords: supply chain innovation, logistics technology, innovative logistics, hypotheses.

\section{INTRODUCTION}

The study has been prepared on the expectations \& response of customers on the use of Logistics Technology in Supply Chain Management. This study is performing an analysis on the use of innovative logistics technology of DHL and FedEx. It provides an in-depth understanding of the impacts that the logistic technology of an organization has on the customer's expectations and satisfaction. It mostly contributes to the customer's satisfaction in the long run. Contextually, the study aims to analyze the customers' responses on their expectations as well as the satisfaction level about the inclusion of the innovative logistics technology in the supply chain management. However, the objectives, which have been adequately addressed in this study for accomplishing the stated research aim are as follows:

- Evaluating the generalized concepts of the supply chain, logistics technology, and customer expectations

- Exploring the impact of the supply chain in the customer expectation management

- Assessing the factors driving the management of customer expectations in two different companies namely DHL as well as FedEx.

Moreover, two sets of hypotheses have been generated in this study and have later on been tested using empirical research tools. The two sets of hypotheses for analysis have been provided below: 


\section{Hypothesis for DHL}

$\mathrm{H}_{0}$ : The incorporation of logistics technology in the supply chain of DHL has resulted in a positive impact on customer expectation management.

$\mathbf{H}_{\mathbf{1}}$ : Logistics Technology when integrated with the supply chain of DHL has not been able to pose a positive impact on its customer expectation management.

\section{Hypothesis for FedEx}

$\mathbf{H}_{0}$ : The implementation of logistics technology in the supply chain of FedEx has a positive impact on its customer expectation management.

$\mathbf{H}_{1}$ : With the in the incorporation of logistics technology, the supply chain of FedEx does not pose any positive impact on the management of customer expectations.

\section{RESEARCH METHODS}

The study has been conducted on the basis of the use of both qualitative as well as quantitative research approaches. Thus, the data has been collected from both primary as well as secondary sources. The primary data, in this case, has been collected through a questionnaire survey, which involved 50 employees each from FedEx and DHL, i.e., a total of 100 respondents using the random sampling approach. This primary data has then been analyzed on MS Excel software by using the statistical tools of Pearson's correlation along with regression. The findings have therefore been interpreted in the study in the form of empirical contribution for testing the already generated hypotheses.

Furthermore, the secondary data has been collected from reliable as well as authorized sources such as textbooks, scholarly journals, and credible websites such as the company's official pages. These textual data has then been reviewed and evaluated with the support of the analytical method. Besides, the study has been interpreted through the descriptive approach. The outcome of the second approach has been included in the study through two various procedures, one of them, being as the justification of the primary findings and the other in the form of theoretical contributions to the study.

\section{THEORETICAL CONTRIBUTIONS}

According to Lu (2011), the supply chain is the method of developing connection within a group of different organizations with the support of their respective products and/ services. This is mainly to deliver them effectively to the ultimate customers or the final end-users. This concept of supply chain also contributes mostly to enabling the organizations as a whole to add values to their products and/services, before delivering them to the customers. The term 'supply chain' can thus be defined as "a group of interconnected participating companies that add value to a stream of transformed inputs from their source of origin to the end products or services that are demanded by the designated end-users" (Lu, 2011). It has, in this context; it has been stated by van der Vorst (2004) that supply chain involves a sequence of processes to be completed by the participating businesses with full coordination, such as planning, decision making, implementation, and execution. Besides, it also includes the maintenance of the smoother flow of money, material as well as information. This chain of events can be inferred from the illustration provided below (Figure 1): 


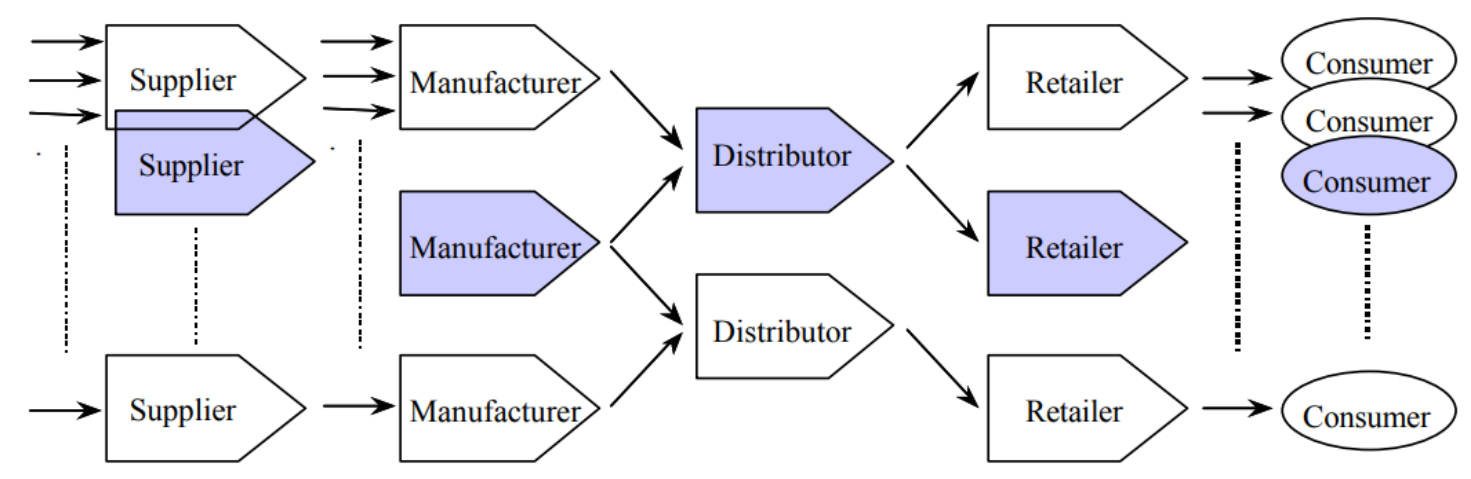

Figure 1: Supply Chain.

Source: van der Vorst, 2004.

Bhandari (2014) had also stated that logistics is a small phase of the supply chain process, which contributes mostly towards planning, controlling, and implementing the forward as well as the reverse flow. Furthermore, it also includes storage of services, related information, and goods. This takes place amidst the point of origin as well as that of consumption to meet the needs of the customers. The most common logistic technologies, which are used by the organizations all around the world in the present scenario, are information technology (Enterprise Resource Planning, automated inventory tracking system, and distribution requirement planning). This also includes Automatic Identification Technology, which encompasses Voice Recognition and Bar Coding among others, and Communication Technology (Electronic Data Interchange). It has further been asserted by Tucci et al. (2015) that the organizations operating under the logistic industry were the initiators of incorporating technologies in their operations for maintaining sustainability, profitability, and leadership in the long run. Furthermore, it has further been stated that these logistics technologies when implemented in the supply chain of different companies also enabled them to develop as well as maximize their profitability over time (Tucci et al., 2015).

Another aspect, which has been adequately covered in this study, is the customer expectation, which has been defined by Saraswathi (2016), as the beliefs of the customers on service delivery. Thus, it further acts as the point of referral, in addition to the standards. In contradiction, the judgment of the performance $s$ made. It is the referral points that are compared by the customers with their perceptions to determine the quality of the services. Therefore, it can be considered a significant issue for the organizations to be able to assess customer expectation effectively to be able to succeed in the long run (Saraswathi, 2016). Additionally, it has further been opined by Thai (2015) that customer expectations may be of two types namely the expected standard, which signifies the "objective calculation of the probability of performance" and the predictive expectations, i.e., meeting the "estimates of anticipated performance level". Both these expectation play a vital role in the service industries, as understanding it from beforehand can enable the companies to enhance the quality of their services, which, in turn, contributes to the improvement of the customers' satisfaction as well as their intention to repurchase (Thai, 2015).

According to Lo et al. (2005), the Supply Chain Management (SCM) approach has been incorporated by the organizations from all genres. This is because historical period significantly focuses on the framing of the operational strategies. This is done to ascertain the completion of the delivery process effectively within the pre-determined time and cost. Over time, significant changes have taken place in this field because of the continuous transformations that have been evident until date. All these aspects pose tremendous effects on the experiences. 
Additionally, the expectations of the target customers further result in the success of the company in the long run. Therefore, it can be inferred that the logistics companies in the present scenario must be well aware of these factors so that their supply chain can be adequately maintained in the long run (Lo et al., 2005). This notion has also been supported by El Shoghari \& Abdallah (2016), who states that effective supply chain management helps in creating an impact on customer services. This also contributes to boosting sales as well as the performance of the companies to a large extent. The primary consideration, in this case, is that every individual associated with the process such as the suppliers, manufacturers, and customers as well as the dealers must possess a proper connection and communication among themselves (el Shoghari \& Abdallah, 2016).

\section{EMPIRICAL CONTRIBUTIONS}

The data collected from the questionnaire survey (refer to appendices) have been prepared in the MS Excel. In this, the correlation and regression analysis have been conducted to test both the hypothesis on whether the technological logistics incorporated by the DHL and FedEx are capable of meeting the customer's expectations. In this context, the technological innovations or the factors were taken into as the independent variables, while the potential of the company to retain the existing customers as well as to attract the newer ones were regarded as the dependent variables.

Table 1: Correlation findings of DHL Company.

\begin{tabular}{|l|l|l|l|l|l|l|}
\hline & $\begin{array}{l}\text { Customer } \\
\text { engagement }\end{array}$ & Factor 1 & Factor 2 & Factor 3 & Factor 4 & Factor 5 \\
\hline $\begin{array}{l}\text { Customer } \\
\text { engagement }\end{array}$ & 1 & & & & & \\
\hline Factor 1 & 0.932222 & 1 & & & & \\
\hline Factor 2 & 0.930761 & 0.886127 & 1 & & & \\
\hline Factor 3 & 0.861131 & 0.84844 & 0.813848 & 1 & & \\
\hline Factor 4 & 0.876644 & 0.921788 & 0.832872 & 0.848493 & 1 & \\
\hline Factor 5 & 0.667526 & 0.624538 & 0.585294 & 0.732467 & 0.775647 & 1 \\
\hline
\end{tabular}

\section{Correlation findings of DHL}

The above Table 1 represents the results of the correlation analysis of the DHL Company. This helps in depicting that the independent (i.e., factors 1-4) and dependent (i.e., customer engagement) variables are directly related. This can be inferred from the fact that all the correlation values are more than 0 and are nearer to 1. It can, therefore, be stated that the implementation of the technological logistics by the company into its supply chain such as the pre-sales technical services, robotics, aftermarket technical services, automated hub proved to be helpful for the company in attracting new customers. Besides, the gateways and DHL parcel metro also were observed to be significantly helpful in retaining the existing ones in the long run.

The information mentioned above can be supported by the fact presented by International Post Corporation (2018) that DHL has been introducing a wide variety of new technologies in its delivery solutions such as logistics. This is to match up to the expectations of the US customers. It is also highlighted that customer expectations have been increasing due to recent trends regarding urbanization, sustainability concern, and e-commerce. These trends have compelled the logistics providers, especially DHL to enhance its services, 
thereby ensuring more efficiency along with flexibility. Some of the technological advancements incorporated in the company include robotics, which encompasses 'sawyer collaborative robots,' LocusBots, and 'augmented reality glasses.' These technologies have been implemented while operating its logistics in the warehouses. Hence, this has proved to enhance productivity, thereby fulfilling the orders of the customers. It also has incorporated automation in its gateways, hubs, and online delivery services. The company to focus on its e-commerce unit has also introduced a new service 'DHL Parcel Metro.' This service mainly aims to provide a flexible and quick logistics services for meeting the increasing demands as well as expectations of the customers (International Post Corporation, 2018).

Table 2: Regression Findings of DHL Company.

\begin{tabular}{|l|l|}
\hline \multicolumn{2}{|c|}{ Regression Statistics } \\
\hline Multiple R & 0.962374 \\
\hline R Square & 0.926163 \\
\hline Adjusted R Square & 0.9196 \\
\hline Standard Error & 0.269668 \\
\hline Observations & 50 \\
\hline
\end{tabular}

\section{Regression analysis findings of DHL}

From Table 2 above, it can be inferred that the R-square value is approximately 0.93 . This is again more than 0 and near about 1 . Hence, it can prove the fact that both the dependent as well as the independent variables are strongly related to one another. Based on these findings, it can further be observed that the first null hypothesis, i.e., "The incorporation of Logistics Technology in the Supply Chain of DHL has resulted in a positive impact on its customer expectation management" gets accepted. Thus, on this basis, the findings of the regression analysis depict that the logistics technologies used in the supply chain operations of the company have maintained its flow of customers. This has ultimately helped in meeting their expectation over time.

This has been evident from the fact that the supply chain of the company has been repeatedly being modified. This has been done by incorporating new and improved technologies right from using robots along with the augmented reality of using artificial intelligence. The company has gradually implemented these changes in almost every aspect of the supply chain so that their logistics services can be improved. Implementing these technologies in the operations of the supply chain of the company has proved to be highly efficient in attaining its objectives, as in the recent context, it has increased the accuracy of shipment by $10 \%$ through the automated hub. It has also succeeded in providing quicker first-time delivery of ecommerce shipments by $12 \%$ (i.e., from the rate of $80 \%$ to $92 \%$ ). Especially, Parcel Metro uses customized software for creating a virtual network for the delivery of the shipments, thereby ensuring maximum capacity and flexibility to the customers. Also, it also increases the last mile prospects. This has enabled the company to provide its customers with flawless experience as well attain their demands a well as expectations, thereby ensuring real-time shipments and better communication with quality assurance in a consistent manner (International Post Corporation, 2018).

Table 3: Correlation Findings of FedEx.

\begin{tabular}{|l|l|l|l|l|l|}
\hline & $\begin{array}{l}\text { Customer } \\
\text { engagement }\end{array}$ & Factor 1 & Factor 2 & Factor 3 & Factor 4 \\
\hline Customer engagement & 1 & & & & \\
\hline
\end{tabular}




\begin{tabular}{|l|l|l|l|l|l|} 
Factor 1 & 0.872561 & 1 & & & \\
\hline Factor 2 & 0.890509 & 0.810287 & 1 & & \\
\hline Factor 3 & 0.909131 & 0.831643 & 0.832569 & 1 & \\
\hline Factor 4 & 0.900797 & 0.910293 & 0.827394 & 0.809703 & 1 \\
\hline
\end{tabular}

\section{Correlation findings of FedEx}

The correlation findings of FedEx are similar to that of DHL and portray a positive value, i.e., above 0, and all are found to be near about 1 . This, in turn, implies that the independent along with the dependent variables are directly related. Such figures, therefore, denote that the implementation of the technological factors including inkjet marking, laser coding, software for serial number generation, product coding, traceability, and Sense Aware device has created a positive impact on the retention as well as attraction rate of the customers. Similar reports have also been presented by FedEx (2018) that it has implemented various technological advancements in its logistics and supply chain processes. It has been using sensorenabled technologies so that the healthcare products are delivered to the customers, undamaged. The products also need to be authentic and in a safe condition. The company has also used the latest technologies for marking products such as laser coding and inkjet marking. These technologies are implemented in the supply chain operations while labeling the assembled systems, products, and its components for uniquely identifying them. The company also has been using the latest software to generate serial numbers as well as manage the coding application in the process of 'packaging execution.' Furthermore, traceability software is also used to avail a platform in which data sharing can be done between the value-chain participants. This includes suppliers in order to track the products (FedEx, 2018).

Besides, it has recently incorporated a device called SenseAware for increasing its logistics capabilities. This device provides real-time data relating to the delivery such as temperature, location, light exposure, and relative humidity. Through this device, sensitive shipments ordered by the customers can monitor the condition of the environment throughout the delivery process. This has been efficient mainly due to the implementation of digitalization in the network of supply chain and the logistics' process. The customers can use this device to monitor the product even inside the shipment container. This has not only retained the existing customers but also has provided a great scope to attract new customers, for example, SmallMedium Enterprises (SMEs). The incorporation of these technologies has ensured cost management for the customers, which has further helped in improving the bottom line services. This is proved by the fact that the customers of the company have been able to set-up and sustains their businesses with mere $£ 1,000(\$ 1,387)$ investment (Table 3).

Table 4: Regression Findings of FedEx.

\begin{tabular}{|l|l|}
\hline \multicolumn{2}{|c|}{ Regression Statistics } \\
\hline Multiple R & 0.959428 \\
\hline R Square & 0.920502 \\
\hline Adjusted R Square & 0.913435 \\
\hline Standard Error & 0.334194 \\
\hline Observations & 50 \\
\hline
\end{tabular}

\section{Regression analysis findings of FedEx}


The R-Square value can be noted in the above Table 4, i.e., approx 0.92 , which portrays that it is independent's variables namely the technological innovation factors are strongly related to the dependent factor. This helps in retaining as well as attracting the customers over time. This can be inferred based on the logic that R-Square value is more than 0 and near to 1 . Moreover, the results gained from regression helps in testing the hypothesis, based on which it can be stated that the second null hypothesis gets accepted, i.e. "the implementation of Logistics Technology in the Supply Chain of FedEx has a positive impact on its customer expectation management." This has also already been proven in the previous section that the technical implementation of the company in its logistics and supply chain network has considerably met the demands and expectations of the customers. It is supported by the reports presented by FedEx (2018) and Henderson (2018) that the company has been ensuring improvement along with the efficiency of its customers in the global competitive market. Moreover, with the incorporation of technologies such as digitalization in the supply chain and Internet of Things (IoT), FedEx has been able to embrace future improvements not only in its operations but also increase its customers' efficiency (FedEx, 2018; Henderson, 2018).

\section{CONCLUSION}

As you can see from the above empirical calculations and its outcome, it is evident that supply chain innovation has positively influenced customer expectation management. It has not only been evident through the statistical analysis, but the theoretical evidence has also supported the findings. It was hence, found that adoption of logistics technology in both DHL and FedEx have a positive impact on the expectations of the customers, in turn enhancing their services. Thus, it has helped in proving the null hypotheses to be true.

Moreover, both the companies have not only met the expectations of the customers but also have managed it. DHL and FedEx also have increased their scope for further improvements, since the demand is gradually increasing. Therefore, it is recommended for the companies that to efficiently manage the expectations of their customers in the future, and they must continue to consider innovation in its supply chain by incorporating latest technologies and digitization. 


\section{REFERENCES}

Bhandari R (2014). Impact of technology on logistics and supply chain management. IOSR J Bus Manage. El Shoghari R, Abdallah K (2016). The impact of supply chain management on customer service (a case study of Lebanon). Management 6(2): 46-54.

https://www.fedex.com/en-us/healthcare/knowledge-center/technology/tracking-solutions-competitive supply-chain-strategy.html https://www.supplychaindigital.com/logistics/interview-fedex-and-exporting-digitised-era https://www.ipc.be/en/news-portal/e-commerce/2018/03/16/09/01/dhl-introduces-new-technologies-anddelivery-solutions-in-us

Lo VHY, Sculli D, Yeung AHW, Yeung ACL (2005). Integrating customer expectations into the development of business strategies in a supply chain environment. Int $\mathrm{J}$ Logis 8(1): 37-50.

Lu D (2011). Fundamentals of the supply chain. Frederiksberg: Ventus Publishing ApS.

Saraswathi S (2016). Service marketing customers expectations and delight. OSR Journal of Business and Management 41-43.

Thai VV (2015). Determinants of customer expectations of service: Implications for fostering customer satisfaction. Int J Manage Appl Sci 1(4): 146-151.

Tucci JE, Shin S, Benefield M (2015). Logistics sustainability: Long-term technology investments and integration. J Manage Sustain 5(2): 48-56.

van der Vorst JGAJ (2004). Supply chain management: Theory and practices. Research Gate. 